\title{
Restructuring, Reform and Refraction: Complexities of Response to Imposed Social Change
}

\author{
Ivor. F. Goodson and Tim Rudd
}

There is a good deal of ongoing debate about the effects and impacts of globalisation. Many educational theorists (eg. Meyer, 1997) have argued that there is a world systems model at work (see Wallerstein, 2004). Meyer and his colleague Francisco Ramirez have developed, from a strong empirical base, the case that many educational reform initiatives resemble 'world movements'. These world movements often change the global rhetoric about education and often originate from global agencies such as the World Bank or O.E.C.D. We would not wish to disagree that a convergent global rhetoric for education has emerged in the neoliberal period.

However, whilst at the supra-level of global policy there are clear indicators of world movements and convergent education rhetorics, this poses the question as to how much impact this has on national and local contexts and on 'policy and practice'. It is therefore possible to envisage a situation where global rhetorics are convergent but national and local policies and practices are divergent. There is a growing body of evidence to show that this is the case. Comparative work employing qualitative indicators and associated data confirm widespread national variations (Green, 2016) whilst qualitative studies in European states (such as the PROFKNOW project) have shown widespread variations in national and local milieu, especially at the level of practice.

What remains under-researched and definitely under-theorised is how and why these variations at the national local level and at the level of practice actually operate. This is vitally important if we are to have an understanding of the substantial variations in the operation of neo-liberal reform initiatives. Whether we view this from the point of view of the reformers, or those unconvinced by the reform, there is a need to understand how variations operate. Not least in importance is the issue of 
'unintended consequences', for if there is no appreciation or understanding of how variations operate. It is distinctively possible that reforms aiming at one objective will operate to fulfil entirely different objectives thereby wasting disproportionate amounts of time and energy.

Over the past decade we have been studying the process of variation which we have come to call 'refraction'. Our work has spanned Europe, South America, the USA and Canada. In each case substantial evidence of refraction was evidenced at national, provincial, local and classroom level (see Goodson and Lindblad, 2010; Goodson, 2014). In the following section we move tentatively towards a theory of refraction

\section{Toward a Theory of Refraction}

This paper further develops the concept of 'refraction' (Goodson \& Rudd 2012; Rudd \& Goodson 2014), which we have been seeking to formulate over the last five years. Refraction is conceived of as a conceptual tool intended to support complex and rich methodological and theoretical explorations of educational discourse, systems, policies and practice. Refraction seeks to simultaneously examine structure and agency and the interrelationships between them, whilst also placing historical and contextual influence at the heart of explorations. Hence we have vertical refraction focussing on structure and agency and historical refraction focussing on the changing historical contexts.

Supra level global trends are seldom interpreted identically in the form of national policies, and similarly, national policies are rarely replicated as intended at the institutional and individual levels. Rather trends and policies are reinterpreted and redirected at local and classroom levels and revised by individuals. This 'refraction' results in global trends being mediated by wider national histories, traditions and dominant ideologies and politics, and national policies being translated through institutional cultures and practice and redirected through action arising based on individuals' and groups' own beliefs, values and trajectories. The resulting translation, or 'bending', occurs in range of different ways and for various reasons and represents a crucial focus for analysis as it may uncover alternative approaches 
and diversity in response, highlight pre-figurative practice and beliefs that influence practice, and illustrates the complex interaction between ideology, structures and institutional and individual action. This complexity requires conceptual and theoretical tools that can support better exploration and investigation, and which may provide richer and contextualised understandings of practice, merely than it being seen as linear or direct responses to change. We argue that the concept of 'refraction' may be seen as one such tool by providing a lens for empirical investigation at the macro, meso and micro levels, as well as providing a simultaneous analysis of both structure and agency through narrative analyses of instances of professional practice and 'episodes of refraction'.

As a concept, 'refraction' draws on a range of existing traditions and approaches but has at its heart a need to explore action in relation to dominant waves of reform and policies introduced into the field, and in particular, in exploring and trying to understand the motivations behind practice that appears at odds with predominant waves of reform. The first constituent aspect of refraction therefore, is the need to situate research and analysis of social change and practice within their wider sociohistorical contexts. This 'historical periodisation' (Goodson \& Lindblad 2010) is essential in locating broader movements, cycles and waves of reform, and also in understanding practice and the extent to which this mirrors or refracts dominant waves, ideology and discourse.

A second and related constituent aspect of refraction is that in investigating and understanding practice and action in a broader social-historical context, we are also better placed to identify and illuminate the effects of ideology and power as exerted through policies and developments in the field and their effects on professional practice and identity. This brings us to the third core component of refraction. Whilst emphasising the need to analyse the effects of ideology and power through the development of policies, this is not determinist and does not occur in a linear fashion. Rather than being passive and subject to the effects of policy, actors are active in the process, often challenging, reinterpreting and mediating policy intentions, which means their action and motivations underpinning chosen courses of action is central to investigations. From our perspective therefore, research and analysis must attempt to address the key dichotomy between structure and agency. In exploring 
this key social scientific dichotomy and investigating both, as well as the relationships between them, we may begin to better investigate the conditions that lead to both loyal compliance and truthful translation of ideology into practice, and perhaps more importantly, the alternative discourses, movements and practice that may arise in response and the motivations behind individual and group actions. Moreover, in elucidating individual narrative accounts of the ways in which actors make meaning of their own lives and professional practice, we are presented with both rich accounts of subjective realities, which will often include detailed examples of varied practices and the generative factors behind them. These portrayals provide us with 'tales' of orthodoxy and transgression, of innovation and conformity, of compliance and resistance, and in considering these in the wider socio-historical context and waves of reform, they provide accounts of the extent and ways in which ideology and power reshapes the educational landscape and influences and configures everyday practice.

\section{Historical periodisation: Cycles and waves of reform as conceptual tools for examining change}

Perhaps the most fundamental aspect of refraction, is that phenomena, in this case educational policy and practice, need to be considered in relation to their social and historical context. Undertaking research and exploring education in relation to a historically situated 'longer view' is far more likely to provide deeper and contextualised insights into the nature and trajectory of change.

There is a long and varied tradition in theory and research, whereby sociologist, economists, historians and others have sought to conceptualise and locate policy development and changes against the backdrop of longer waves, or cycles, of reform (See for example, Tyack and Cuban 1995; Tyack and Tobin 1994; Fontvieille 1990). Such historical analyses provide a better basis for understanding the past, current policy change and directions, and the factors, ideologies and pre-existing conditions and practices underpinning them. Furthermore, historical analyses may also enable us to postulate longer term outcomes and implications of policies and emergent practice, and give us insights into both future possibilities and areas of potential contestation. Whilst theories regarding the nature and regularity of waves of reform vary significantly and give rise to much debate (McCulloch 2011), they at 
least provide a socio-historical context on which to base discussions and theorisation. Arguably, historical periodisation tends to be given scant attention, and instead emphasis is increasingly placed on unique, contemporary possibilities and processes that tend to focus on bringing about changes that reflect the prevailing logic introduced into the system by the predominant ideology through a narrowly defined system and tightly bounded institutional outcome measures. These issues alone might arguably justify the need to adopt a broader socio-historical analysis to policy developments.

Whilst there is a rich history and numerous conceptual models and theories that support analysis of historical epochs and cycles, there is no singular or definitive method or conceptual framework for doing so. Numerous researchers and theorists have studied links between historical cycles of economic growth and educational expenditure (See for example, Lowe \& McCulloch 1998 and Carpenter 2001), with many developing or attempting to apply particular models in doing so.

The Annaliste School combined history and sociology in attempts to understand change, with perspectives on cycles, or waves of reform, argued to occur on three levels, over shorter, medium and longer terms, with the emphases and characteristics of each cycle being distinctive. Longer term waves appear relatively stable (although they are constantly moving) and are linked to core structural factors and world views. Medium term waves tend to be signified by cycles of boom-bust lasting approximately 50 years, and provide a lens through which to examine the development of many key systems, including education, and which may provide insights into future directions, reforms and possibilities. Shorter term waves of reform focus on more discrete periods and particular politics and policies but are also representative of everyday events and human actions, providing specific empirical insights into action. Whilst each may be viewed as competing models, they are often viewed as interwoven and interdependent, and indeed, complimentary approaches. Whilst there have been numerous refinements and reinterpretations of these 'waves' of reform, from our own conceptual standpoint the development of refraction requires consideration of 'waves of reform' and action occurring at all three levels simultaneously, although there is clearly much opportunity and need to debate the length and timing of each cycle. 
Economists have long considered historical periods as a basis for analysing change and 'business cycles' and predicting future developments and trends as a result. For example, Schumpeter (2006 [1939]; 1954) drew on identified models of macroeconomic activity to present a composite wave-form. Although Schumpeter did not propose a fixed or rigid mode, and suggested such cycles varied in time and existed for very different, rather than necessarily interrelated or interdependent purposes, others have drawn on his model to suggest that waves may be inextricably linked. From this perspective it is suggested that a longer 'Kondratiev wave', or 'long wave' (between 45-60 [54] , years and denoted by cycles incorporating alternating periods of both high and slow growth), may also consist of something similar to three Kuznets demographic cycles or 'building swings' (15-25 [18] years), sometimes interpreted and termed as medium term infrastructural investment waves. Similarly, it has been asserted that each Kuznets wave itself may be made up of two Juglar waves of fixed investment (7-11 [9] years), which are arguably denoted by observable cycles and changes in investments into fixed capital. Similarly, each of the Juglar waves, may comprise 2 'Kitchin inventory cycles' (3-5 [4.5'] years). These relatively short cycles are accounted for by the time lags between changes and improvements in external conditions and the time it takes commercial organisations to increase outputs and respond to the new conditions. These cycles tend to enter a decline once the market becomes flooded and there is a decline in demand, which can trigger subsequent reduction in outputs.

From such a perspective, economic crashes and subsequent deep depressions will occur when the downward trajectories of each of the four waves correspond. However, when trying to apply such models, there will be significant debate regarding the precise start and end of each cycle, how each is denoted, whether they are inextricably linked, and whether and to what extent each one is, or should be, viewed as either an retrospective explanatory model and/or predictive indicator of change.

\footnotetext{
${ }^{1}$ The broader range in number of years is presented first. The figure in brackets is not a precise figure but is presented for illustrative purposes to demonstrate the possibility for composite and interlinked cycles. ${ }^{2}$ Many commentators suggest a Kitchin cycle lasts around 40 months but there is much debate as to the length of the cycle
} 
Whilst there is a debate to be had about the suitability and appropriateness of utilising models that attempt to explain and predict economic cycles when we theorise educational change and the related responses, it is clear they provide conceptual tools to support our thinking about historical periodisation, which is clearly a fruitful area for further development in education. Although it may be easier to analyse business cycles and forms of financial investment than it might be to explore other aspects of social development, there are clearly often close relationships between them. However, the development of further models specifically addressing the peculiarities, specifics, histories, and indeed the requirements for education that may extend beyond the current needs of neo liberal capitalism, may all be valuable additions. As Schumpeter himself argued, when examining capitalism, it can only truly be understood as an evolutionary process of innovation and 'creative destruction' encapsulating both periods of economic growth and also contraction and instability, and which involves interactions between multifarious variables, structures, systems and actors. Whilst existing models may be of great conceptual value, there are numerous factors that may undermine their predictive utility. Unexpected events, technological developments, or unique corresponding incidents can make nonsense of expectations that such models may offer an 'exact science'. One only has to reflect on recent events affecting economies in the West, and elsewhere, to consider whether, or what types of waves, may be in their downward trajectories. Interestingly, Schumpeter also predicted that capitalism would collapse, progressively weakening and becoming self-defeating, and would eventually be replaced by a new form of socialist corporatism seeking to reign in capitalisms excesses and inclinations toward damaging boom and bust. However, recent policies, in the UK at least, do not appear to be diverging from the predominant form(s) of neo liberal capitalism. Nonetheless, identifying the prevailing power and ideology that characterises each historical period, and how it is translated into systems and practice, must remain central to analyses.

\section{Uncovering ideology and power in restructuring policy and practice}

Historical periodisation requires analysis of socio-historical trends, which can vary significantly and are refracted in different continents and cultures. For example, the 
Professional Knowledge Project (see: Goodson \& Lindblad op. cit.) studied professional life and work in seven European countries. It identified distinct variations in historical periods in each country, although the trend for more neo-liberal informed restructuring ultimately became an identifiable broad-based movement across all countries, albeit being mediated by nation specific foundations and trajectories. In identifying these periods, it became better understood how the restructuring of education policies and the wider discourse affects the working lives and professional narratives of people who were expected to implement changes on the ground. By way of illustration, the periods relating to the context in the UK are presented below ${ }^{3}$.

Table 1: Historical periods and key policy discourse in the U.K.

\begin{tabular}{|c|c|}
\hline Periods & $\begin{array}{l}\text { Basis for distinction and key policy } \\
\text { discourse }\end{array}$ \\
\hline $\begin{array}{l}\text { 1945-1979: Progressive narrative on } \\
\text { welfare state expansion }\end{array}$ & $\begin{array}{l}\text { Rapid Welfare State expansion. } \\
\text { Patterns of profit and accumulation linked } \\
\text { to development of the welfare state. } \\
\text { Comprehensive and universal guarantee } \\
\text { of 'cradle to grave' provision of minimum } \\
\text { income, social protection and health and } \\
\text { welfare service provision. }\end{array}$ \\
\hline 1979-1997: Marketisation narrative & $\begin{array}{l}\text { The neo-liberal breakthrough as an } \\
\text { organising principle. New emerging } \\
\text { patterns of profit and accumulation. } \\
\text { Comprehensive welfare expenditure } \\
\text { increasingly seen as a 'burden' and } \\
\text { increasingly reframed as a drain on } \\
\text { national resources in light of global and } \\
\text { national economic crises. Promotion of } \\
\text { ideas to promote free markets and } \\
\text { competition and a questioning of the }\end{array}$ \\
\hline
\end{tabular}

\footnotetext{
${ }^{3}$ The table presents an overview of key policy discourse in identifiable historical periods in the UK. The original Profknow research included responses only from English participants, on which this amended table is based.
} 


\begin{tabular}{|c|c|}
\hline & $\begin{array}{l}\text { principles of comprehensive and } \\
\text { universal welfare provision. }\end{array}$ \\
\hline $\begin{array}{l}\text { 1997-2007: Narrative of 'third way' } \\
\text { politics }\end{array}$ & $\begin{array}{l}\text { 'New' third way politics. Modernised } \\
\text { 'New' Labour Party moves to the 'middle } \\
\text { ground' but arguably continues to } \\
\text { support preceding privatisation and } \\
\text { marketization agendas. Middle way } \\
\text { policies promote growth of targets, tests } \\
\text { and tables. }\end{array}$ \\
\hline $\begin{array}{l}2007 \text { - ?: The reconstituted neo liberal } \\
\text { Period and discourse of austerity? }\end{array}$ & $\begin{array}{l}\text { The 'reconstituted neo-liberal period'? } \\
\text { Crisis of capitalism and discourse of } \\
\text { austerity. Reaffirmation of neo-liberalism } \\
\text { values of reducing state expenditure and } \\
\text { public services and promotion of private } \\
\text { ownership and investment. }\end{array}$ \\
\hline
\end{tabular}

Even given the rather crude and limited depiction above, we might begin to debate whether, or to what extent, each of these periods reflects a wave or cycle of reform, what type of cycle it might correspond with, or indeed whether some of the periods outlined are merely surface re-presentations of their predecessor. There is much debate regarding the changes since the economic crisis of 2007, and whether, in relative terms, the emerging trends that can be identified will be long lasting enough to constitute the beginning of a new wave of reform, whether they are a continuation or refinement of their predecessor, or conversely, whether we are in fact merely witnessing the beginning of the end of a much longer wave of reform.

Nonetheless, in understanding the current socio-historical period, or what we refer to as the 'reconstituted neo liberal period', it may be argued that the predominant discourse forcibly promotes 'austerity' policies aimed at promoting a new form of neo liberalism, with economic claims underpinning sizable reductions and redistributions of central Government spending in the public sector. For example, the scale of the sale of public assets under the five and a half years the current Chancellor of the 
Exchequer (George Osbourne) has been in post, amounts to $£ 37.7$ billion, with a further $£ 20$ billion worth intended to sold off before the next financial year (April 2007), which would be a greater amount than any chancellor since 1979 (cf. McTague 2015). Such activity has also been allied the promotion of greater private sector involvement in public sector provision and services, including the education sector. Whilst there is not space to provide a detailed review of policy developments in education, key, fundamental changes include the promotion of Academies and free schools, which promote the growth of private (as well as charitable) involvement through sponsorship and the setting up of schools free from local authority control. The Secretary of State had already been granted power to issue academy orders to 'under-performing' schools, however, in a recent and striking development, the Chancellor of the Exchequer, has laid out plans for all state schools to be converted to Academies. The supporting political discourse implies that academisation will lead to improved school performance, with clear little supporting detail. However, some authors suggest that the evidence to support such claims remain debatable at best. It is further contended that such moves are little more than ideologically informed developments to support private involvement, supported by numerous existing vested interests within existing academies and educational services sector. Additionally, it is also argued that there are millions of pounds being spent on tax payer funded conversion costs, arguably a potential further incentive and source of income for private interests and profit, that are being conveniently overlooked as they would clash with the wider 'austerity discourse' being perpetuated to support 'reconstituted neo liberal policy developments'(See: Philips (forthcoming).

In many respects, changes in Higher Education have also been a 'game-changer', with a fundamental shift in emphasis and a lifting of the cap on tuition fees. This arguably reflects both the 'austerity discourse' and a wider market model by placing fee paying students firmly in the role of consumer, or customer, and practitioners and Higher Education institutions, arguably as service providers. Subsequently, we have already seen associated practice and processes that place greater emphasis on customer (student) satisfaction through large scale data collection used as proxy measures to imply 'provider quality ratings' and value for money provision. In keeping with the broader promotion of private enterprise and restraints in the public sector, the Higher Education White Paper (Department for Business Industry and 
Skills 2011) promotes more collaboration with industry and has potentially paved the way for a greater number of 'service providers' to join the Higher Education sector, as well as calling for greater accountability in Higher Education. In this respect, we have also witnessed the growth of new methods and mechanisms intended to monitor and 'guarantee' professional and institutional quality of service, with further frameworks, such as the introduction of a 'teaching excellence framework' (TEF), imminent. Similar excellence frameworks for research (the Research Excellence Framework (REF) and its predecessor the Research Assessment Exercise (RAE) have been around for some time, yet there has been an increased emphasis on research quality and (arguably narrowly defined) impact, with a plethora of measurements, monitoring mechanisms and managerial processes and committees coming into existence within the system and in institutions, especially following the reduction and redirection of funding from Research Councils and other sources.

It is clear that recent policies and shifts have fundamentally changed the educational landscape, and have formulated education around principles quite distinct from those underpinning the earlier development of comprehensive state education for all.

In our analysis of educational policy making and practice, it is vital to have an intensive understanding of historical developments and wider ideological and policy trends that lead up to and influence current day policies and practice. Not only does this give a greater sense of the context and likely future developments, it can also provide insights into which policy developments may work, or indeed which are likely to be refracted, in the future. However, it is perhaps most important in order to locate and understand the type and extent of policy refraction that may occur through institutionally based, group and individual practice. Nonetheless, if educational institutions, as Bourdieu (1977; 1977a) suggests, are sites of social and cultural reproduction, we cannot overlook the effects that power, ideology and related policy making has on the practices within such sites and the orthodoxy, 'rules' and 'logic' (Bourdieu 1993) it may infer or transmit, and what effects there are on subsequent practice as a result. This is fundamental to holistic explorations and enables clearer understanding of agency and the ways in which actors may, or indeed may not, actively respond to, or accept, symbolic power being exerted in the field (Bourdieu 
1999). However, responses are likely to vary significantly from nation to nation, influenced to some degree, by pre-existing histories and traditions.

In the Professional Knowledge Project (Goodson \& Lindblad op. cit.), the broad responses in seven different countries to recent neo-liberal restructuring policymaking waves were analysed. At the national level, responses varied from fairly compliant integration, which was most evident in England, to those characterised by contestation and resistance, most evident in the Southern European countries, through to 'decoupling' responses, interestingly evident in the more 'successful' educational systems of Finland, and to a lesser degree, Sweden. This demonstrates how national systems, structures and histories can lead to political refraction of various guises in response to wider globalising forces and movements.

Table 2. Restructuring tools and strategies and work life narratives

\begin{tabular}{|c|c|c|}
\hline $\begin{array}{c}\text { Policy Discourses as } \\
\text { System Narrative }\end{array}$ & $\begin{array}{c}\text { Restructuring Tools and } \\
\text { Strategies }\end{array}$ & Work-Life Narratives \\
\hline $\begin{array}{c}\text { Restructuring Policy- } \\
\text { making }\end{array}$ & $\begin{array}{c}\text { Implementation } \\
\text { Responses and } \\
\text { Strategies }\end{array}$ & Professional Work/Life \\
\hline $\begin{array}{c}\text { Restructuring Policy- } \\
\text { making }\end{array}$ & Integration & $\begin{array}{c}\text { Reconstructed } \\
\text { Professional }\end{array}$ \\
\hline $\begin{array}{c}\text { Restructuring Policy- } \\
\text { making }\end{array}$ & Contestation & Contested Professional \\
\hline $\begin{array}{c}\text { Restructuring Policy- } \\
\text { making }\end{array}$ & Resistance & Resistant Professional \\
\hline $\begin{array}{c}\text { Restructuring Policy- } \\
\text { making }\end{array}$ & Decoupling & Decoupled Professional \\
\hline \multicolumn{2}{|c}{} \\
\hline
\end{tabular}

Following national responses to restructuring, it was then possible to identify empirically work-life narratives arising in relation to the new conditions and emerging 
orthodoxies. When juxtaposing systemic narratives and work life narratives, it must be considered that there are numerous points of refraction through which restructuring policies must pass, from national and regional systems, interest groups, boards and committees, through to individual institutions, each having an 'interpreter effect' and mediating intended outcomes and practice. This interpreter effect might be thought of as something akin to (much debated) theories emanating in the field of neuropsychology (Gazzaniga, 2005), whereby the ('left hemisphere') interpreter attempts to generate and construct explanations by reconciling emerging information through reference to the past and what was previously known and understood. In attempting to reconcile the past and the present, previous practice and beliefs may not only provide a sense of coherence to professional identity, it can also provide a sense of security and degree of ownership over policies that may be imposed by others. When we consider power and policies in relation to individual practice, we identify fertile spaces for empirical and narrative investigation of the beliefs, prefigurative practices and experiences that influence actors, and which may result in a range of different dispositions and actions ranging from resignation, conformity, unconscious acceptance and compliance, on the one hand, to latent and wilful oppositional practice and resistance, on the other.

\section{Exploring structure and agency: The dialectical challenge in understanding refraction}

In one sense, practice can be seen as a process of active interpretation, and a mediated outcome between structure and agency. The opportunity for reinterpretation of structure and discourse is dependent on prior experiences and pre-figurative practice, the level of possession of various individual and collective capitals that have value in any given context, and subjective expectations of objective possibilities (Bourdieu 1977; 1990) for new and alternative courses of action and change. This dynamic interplay between structure and agency, capitals and context, gives rise to the dynamism inherent within social practices and results in the plethora of courses of action and routes for refraction. These need to adequately considered in educational practice and research, as failure to do so may lead to research of limited scope and truncated findings. It is perhaps in such 
uncertain periods that we conversely need to bring into sharper focus the varied and diverse practice and refractions.

As a methodological and theoretical concept, refraction offers a means through which to simultaneously focus on both structure and agency and the dynamic interrelationships between them, which has long been viewed as a key dialectical challenge for the social sciences (Berger and Luckmann 1966). We suggest that structure and agency are both competing and complementary forces, with power, structures, and fields (Bourdieu 1984) having often significant effects on action and behaviour. Moreover, we recognise the potential for individual and collective action that can mediate the effects and intent of restructuring policies and which may lead to new and unique practices in response to the prevailing logic, and in so doing, hope to avoid structural determinist assumptions.

Fig.1. Interrelationships: Structure and agency and histories and trajectories 


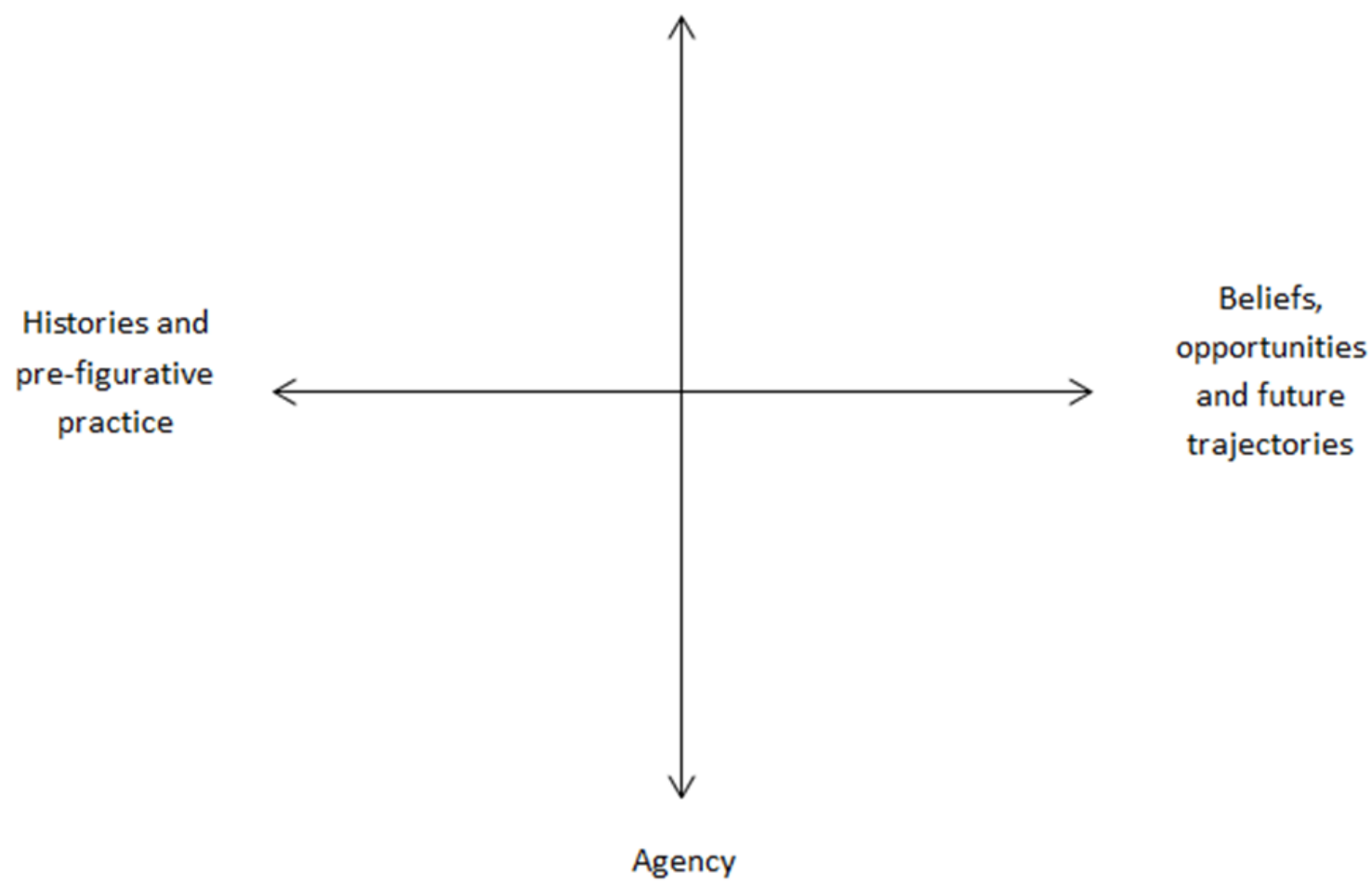

A key to understanding any human action is through 'practice', yet practice should not be considered free from both its individual and structural generative conditions. In other words, practice should not be considered free from human agency and the experiences, pre-figurative practices and beliefs that may contribute to reinterpretation, redefinition and refraction, as well as 'misrecognition' in social practice arising through misattribution of wider generative structures and failures to recognise the social differentiation these may maintain and reproduce (Bourdieu 2000). Indeed, this highlights the need to not only look at relationships between power, policy and professional narratives and individual practice in education but to also consider whether individual and institutional practices have become normalised as a result of the conditions arising from the generative structures themselves (Grenfell and James 1998) and which are exerted through new orthodoxy and doxa (Bourdieu 1984). In short, we must be aware that action is not free from power, and the structural and ideological factors and conditions that can place practical limitations on individual practice.

From our perspective, in developing the concept of refraction, we seek to provide a more holistic analysis that considers the interconnectedness between structure, 
agency, ideology and histories and beliefs. Moreover, we emphasise the need to explore professional narratives and experiences that lead to re-contextualisation, decontextualisation and refraction of education policies.

Figure 2. (below) is an attempt to represent the 'axes of refraction' in relation to UK waves of reform in order to broadly illustrate the various foci for analysis and 'spaces' where refraction may occur.

We seek to show the levels at which refraction operates in terms of vertical systems from the supra or global level of policy-making through the national systems level, or macro level, and to the meso level where national policies and processes interact with sectoral and interest groups as well as professional and associated pressure groups. The final level, which is perhaps the most intensively researched, is the interaction between top-down generated policies and school and classroom groups and ultimately individual teachers. Each of these vertical levels constitute a potential site of refraction and it is of course possible that re-direction at each level may for instance provide sharp redirections of policy or even complete u-turns as each level reformulated and redirects the policy trajectory. The unintended consequences of reform need then to be interrogated and understood at each site of refraction. This requires that we view the policy process as an interested vertical process that merely looking at how policy is received and reformulated at the level of the school or classroom is an inadequate and partial form of analysis.

The other site of refraction is the horizontal level of historical periodicity. As we noted earlier, the work of the annaliste school of historians is invaluable in researching and analysing this level of refraction as historical periods designate different 'windows of opportunity' for the delivery and operation of policies - one only has to juxtapose the period of the building of the welfare after 1945 with the current period of marketization to see how radically historical circumstances refract the policy process. In this case we are back with Marxist statement that 'men make their own history but not, in circumstances of their own choosing'. Hence we must study how historical periods resignated particular and specific conditions for the delivery and operation of policies. 
Fig. 2. Axes of Refraction: Horizontal and vertical refraction

\begin{tabular}{|c|c|c|c|c|c|}
\hline \multirow{10}{*}{ 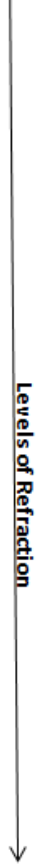 } & $\begin{array}{l}\text { Supra } \\
\text { Level }\end{array}$ & $\begin{array}{l}\text { Global ideology and } \\
\text { restructuring narratives }\end{array}$ & & & \\
\hline & \multirow{2}{*}{$\begin{array}{l}\text { Macro } \\
\text { Level }\end{array}$} & $\begin{array}{l}\text { National systems, structures, } \\
\text { ideology }\end{array}$ & & & \\
\hline & & $\begin{array}{l}\text { National restructuring } \\
\text { policies }\end{array}$ & & & \\
\hline & \multirow{3}{*}{$\begin{array}{l}\text { Meso } \\
\text { Level }\end{array}$} & $\begin{array}{l}\text { National decision making } \\
\text { processes and interests }\end{array}$ & & & \\
\hline & & Sectoral and interest groups & & & \\
\hline & & $\begin{array}{l}\text { Professional and pressure } \\
\text { groups }\end{array}$ & & & \\
\hline & \multirow{2}{*}{$\begin{array}{l}\text { Micro } \\
\text { Level }\end{array}$} & Smaller groups & & & \\
\hline & & Individuals & & & \\
\hline & & $1945-1979$ & 1979-1997 & $1997-2007$ & $2007-?$ \\
\hline & & $\begin{array}{l}\text { Progressive narrative on } \\
\text { welfare state expansion }\end{array}$ & Marketisation narrative & $\begin{array}{l}\text { Narrative of the middle way: } \\
\text { targets, tests and tables }\end{array}$ & $\begin{array}{l}\text { The reconstituted neo } \\
\text { liberal period and discourse } \\
\text { of austerity? }\end{array}$ \\
\hline & & & \multicolumn{3}{|l|}{ Historical Periods } \\
\hline
\end{tabular}

The ' $x$ ' axis (using the UK as an example) represents key historical periods, whilst the ' $y$ ' axis highlights various levels of societal action. These range from the supra and macro structural levels through which restructuring discourse emanate and are interpreted into policies, through to the meso and micro levels through which such policies are mediated and reinterpreted into practice. Such practice itself will vary from that which is more closely aligned with other pre-figurative practice and beliefs, or conversely, with that which is more loyal to, and compliant with, dominant discourse and new and emergent orthodoxies.

Considering how we might use this illustration to inform empirical investigation, at any level, moving from the columns on the left to the right, we might postulate any potential influences and relationships there may be with preceding historical periods, experiences and beliefs and consider how they may shape, influence and lead to 
opportunities or 'moments of refraction' in practice. These 'moments of refraction' are therefore crucial foci for empirical investigation.

Moreover, if we also investigate and plot restructuring discourse and its translation to into policies and practice through the various systems, structures, contexts and practice operating at various levels (from top to bottom represented in any respective column), we are then better placed to see where, how, and to what extent, refraction of restructuring policies occur, and the interrelationships, compliance and/or dissonance occurring between structure and agency. Whilst exploring these factors simultaneously may present us with a detailed exploration of both the generative and regulative factors that underpin social practice, they are most profitably explored through 'thick' description and rich narrative portrayals that emphasise and illustrate key empirical focal points, or 'episodes of refraction' (represented by action that might be presented in any single 'cell' within the table).

Of course, this is clearly an oversimplification, and thorough analysis would require developing detailed empirical evidence to explore any interrelationships and to uncover tangible examples, if and where they exist, yet this represents an early attempt to lay out the key constituent parts and conceptual elements of refraction.

\section{Conclusion}

Refraction demands explorations of supra, macro and national movements, policies and structural regulation and how these are interpreted and reinterpreted through meso level organisational culture, decisions and initiatives and contextualised, decontextualised and re-contextualised through micro level interactions. The numerous contexts and multiple possibilities that arise through the interactions between structure and agency provide space for reinterpretation and variation through action. Undertaking narrative enquiry to understand the generative and regulatory factors underpinning action, and the origins of professional identities and changes in practice, are rich empirical sources through which to contextualise practice against broader historical periods, trends and trajectories. These trajectories of refraction too, need to be critically examined in terms of power, ideology and symbolic violence that can set parameters to perceived possibilities for social action and practice. However, we must 
also avoid assumptions and explore and challenge linear perceptions of causality, by exploring alternate interpretations and practice arising. Although it may sometimes be uncomfortable, perhaps the most interesting and fruitful areas for exploration are those points of refraction where policy is subject to interpretation at different levels of power, and when different layers of historical time coincide, as these may provide crucial insights into the possibilities for change and reform.

What the refraction process warns us of is the 'unintended consequences' of symbolic changes and initiatives at the Governmental level. What sets out as being a reform with clear intentions and objectives is actively reinterpreted and reinterpreted at each stage of refraction. On the long journey of school or institutional knowledge, the only way to understand these reinterpretations is to show sensitivity and sympathy to the life missions and intentions involved at each refractive stage. Without this narrative knowledge and without narrative learning, Government intentions can have grievously counter-productive results. It is time therefore to broaden the scope of our research on policy-making and the broad span of the policy process and its subsequent operation.

\section{$\underline{\text { References }}$}

Berger, P., \& Luckmann, T. (1966) The Social Construction of Reality: a treatise in the sociology of knowledge, Garden City, New York: Anchor Books.

Bourdieu, P. (1977) Outline of a Theory of Practice, Cambridge University Press: London.

Bourdieu, P. (1977a). 'Cultural Reproduction and Social Reproduction'. In Karabel, J and A. H. Halsey (1977) Power and Ideology in Education. Oxford, OUP.

Bourdieu, P. (1984). Distinction: A Social Critique of the Judgement of Taste. London, Routledge

Bourdieu, P. (1990). The Logic of Practice. (trans. Richard Nice). Stanford University Press.

Bourdieu, P. (1993). The Field of Cultural Production', New York, Columbia University Press. 
Bourdieu, P. (1999). 'Postscript', in P. Bourdieu et al., The Weight of the World: Social Suffering in Contemporary Society. London: Polity.

Bourdieu, P. (2000). Pascalian Meditations. (R. Nice, Trans.). Cambridge: Polity Press.

Carpentier, V. (2003) 'Public Expenditure on Education and Economic Growth in the UK, 1833-2000'. History of Education, 32(1), 1-15.

Carpentier. V. (2001). Developpement educative et Performances Economiques au Royaume-Uni: $19^{\text {th }}$ and 20th Siecled, Paris: L'Harmattan.

Department for Business, Industry and Skills (2011). Higher Education White Paper: Students at the Heart of the System. London: Crown, Department for Business, Industry and Skills.

Fontvieille, L. (1990). 'Education, Growth and Long Cycles: The Case of France in the $19^{\text {th }}$ and $20^{\text {th }}$ Centuries', in G. Tortella (ed.) Education and Economic Development since the Industrial Revolution, Valencia: Generalitat Valenciana, 317-335.

Gazzaniga, M. S. (2005). The Ethical Brain. New York, Dana Press.

Goodson, I. F (2014) Curriculum, Personal Narrative and the Social Future. London and New York: Routledge.

Goodson, I. F. \& Lindblad, S. (2010). Professional Knowledge and Educational Restructuring in Europe. Sense. Rotterdam/Boston/Taipei.

Goodson, I. F. \& Rudd, T. (2012) 'Developing a Concept of Refraction: Exploring Educational Change and Oppositional Practice'. Educational Practice and Theory 34(1) 2012.

Goodson, I. F. (2005). Learning, Curriculum and Life Politics: The Selected Works of Ivor F. Goodson. Routledge, Oxford.

Green, A. (2016) Paper presented at 'The Rise of Global Education Policy and National Reforms: How far are National Education Systems Converging?' At the SEC-SPCE Conference 'Comparative Education beyond the numbers: local contexts, national realities and transnational processes', Lisboa, 25-27 January.

Grenfell, M. \& James, D. (1998). Bourdieu and Education: Acts of Practical Theory. Falmer, London.

Lowe, R. and McCulloch, G. (eds.) (1998), 'Education and Economic Performance'. Special issue, History of Education, 27(3). 
McCulloch, G. (2011). The Struggle for the History of Education. Abingdon, Routledge.

McTague, T. (2015). 'George Osborne on Course to Privatise More Public Assets Than Any Chancellor since 1979'. The Independent, 26 th December 2015. (P.3).

Meyer, J,. Boli, G., and Ramirez, F. (1997) 'World Society and the Nation-State' American. Journal. of Sociology ,103, 1. July 1997: pp. 144-81.

Meyer. J. (2000) 'The World Institutionalization of Education', pp. 111-32 in J. Schriewer, ed., Discourse Formation in Comparative Education, Frankfurt: Peter Lang.

Philips, D. (forthcoming). 'Education Free for All: Outsourcing, Contracts and Conflicts of Interest in the UK', in T. Rudd \& I. F. Goodson, Negotiating Neo Liberalism: Developing Alternative Educational Visions. Sense.

PROFKNOW Project (2003-2008) Professional Knowledge in Education and Health Restructuring Work and Life Between State and Citizens in Europe University of Brighton - UK, University of Gothenburg - Sweden, National and Kopodistorian University of Athens - Greece, University of Joensuu Finland, University of Barcelona - Spain, University of the Azores Portugal, St. Patrick's College, Dublin City University - Ireland, University of Stockholm - Sweden.

http://cordis.europa.eu/result/rcn/51693 en.htmIRudd, T. \& Goodson, I. F. (2014). 'Studying Historical Periodisation: Towards a Concept of Refraction', ' in A. Teodoro \& M. Guilherme, European and Latin American Higher Education Between Mirrors: Conceptual Frameworks and Policies of Equity and Social Cohesion, Rotterdam / Boston / Tapei, Sense Publishers, 139-154.

Schumpeter, J A. (2014) [1942]. Capitalism, Socialism and Democracy (2nd ed.). Floyd, Virginia Impact Books.

Schumpeter, J. A. (1954). History of Economic Analysis. London, Allen \& Unwin. Schumpeter, J. A. (2006) [1939]. Business Cycles: A Theoretical, Historical, and Statistical Analysis of the Capitalist Process. Mansfield Centre, Connecticut: Martino Publishers. 
Tyack, D., \& Cuban, L. (1995). Tinkering Toward Utopia. A Century of Public School Reform. Cambridge, MA.: Harvard University Press.

Tyack, D., \& Tobin, W. (1994) 'The 'Grammar' of Schooling: Why Has it Been so Hard to Change?' American Educational Research Journal, 31(3), 453479, Fall.

WALLERSTEIN, I. (2004) World-Systems Analysis: An Introduction. North Carolina: Duke University Press.

Ivor Goodson

Professor of Learning Theory

\section{Tim Rudd}

Principal Lecturer

Education Research Centre

University of Brighton

Checkland Building

Falmer

East Sussex

BN1 9PH 